\title{
The Judgement for Development of Virtual Surgical Planning and Three-Dimensional Bio-Printing for Superior Reconstruction of Mandibular Defect by Fibular Graft on Head-Neck Cancer
}

\author{
Nadia Sultana Shuborna ${ }^{1}$ (D), Bishwa Prakash Bhattarai ${ }^{2}$ (D) Teeranut Chaiyasamut $^{1}$ (D), \\ Sirichai Kiattavornchareon ${ }^{1}\left(\mathrm{D}\right.$, and Natthamet Wongsirichat ${ }^{3}$ iD \\ ${ }^{I}$ Department of Oral and Maxillofacial Surgery, Faculty of Dentistry, Mahidol University, Bangkok; and \\ ${ }^{2}$ Department of Clinical Dentistry, Walailak University International College of Dentistry, Bangkok; and \\ ${ }^{3}$ Consultant of International College of Dentistry Committee, Walailak University International College of Dentistry, Bangkok, Thailand
}

\author{
Received August 11, 2020 \\ Revised October 14,2020 \\ Accepted October 19, 2020 \\ Address for correspondence \\ Natthamet Wongsirichat, \\ B.Sc., D.D.S., Cert. \\ in Oral \& Maxillofacial Surgery, \\ Cert. in the Advanced Programme \\ of Oral \& Maxillofacial Surgery \\ (Osaka), Diplomate, \\ Thai Board of Oral \& Maxillofacial \\ Surgery \\ Consultant of International \\ College of Dentistry Committee, \\ Walailak University International \\ College of Dentistry, \\ 979/42-46 Phahonyothin Road \\ 19th floor SM Tower \\ Phaya Thai District, \\ Bangkok 10400, Thailand \\ Tel +6622990935 \\ E-mail natthamet.wo@wu.ac.th
}

Oncological resection followed by reconstruction with a free fibular graft is still considered to be the gold standard treatment for functional and prosthetic rehabilitation of oral cancer patients. But this tedious traditional process is challenging for surgeons, as they have to deal with associated curve anatomy, surrounding innervations, and maintenance of functional and aesthetical acceptability. Such manual and operator's skill dependent surgery can commonly demand a longer treatment duration; leading to an increased risk for prolonging the period of ischemia with increased morbidity, which frequently ends with an uncertain, unsatisfactory outcome. Technological advancements in the 20th and 21st centuries present a revolutionary improvement in the field of reconstructive surgery. Virtual surgical planning (VSP) and threedimensional (3D) bio-printing incorporating computer-aided design and computer-aided modeling is a promising tech in modern head and neck reconstruction. This recent innovation is more polished regarding initiation of patient-customized models, pre-bent plates, and osteotomy guides which further increase surgical precision, improve operative efficiency, ensure proper wound healing, shorten operative time, reduce operative cost, and decrease morbidities. This review focuses on the virtual surgical planning and 3D bio-printing technologies to evaluate their efficiency of qualitative and quantitative outcomes of resection and reconstruction of mandible in head-neck cancer using fibular graft.

Korean J Otorhinolaryngol-Head Neck Surg 2021;64(3):135-47

Key Words Computer-aided design and computer-aided modeling system •

Fibula free graft · Mandibular reconstruction ·

Oral squamous cell carcinoma $\cdot$ Virtual surgical planning $\cdot 3 \mathrm{D}$ printing.

\section{Introduction}

Oncological resection of the mandible creates a miserable aesthetical and functional deficit that results in physical, functional, nutritional as well as psychosocial impairments compromising the patient's residual life standard. ${ }^{1,2)}$ Corrections

This is an Open Access article distributed under the terms of the Creative Commons Attribution Non-Commercial License (https://creativecommons.org/licenses/by-nc/4.0) which permits unrestricted non-commercial use, distribution, and reproduction in any medium, provided the original work is properly cited. of these types of defects require a compound plan. Hidalgo ${ }^{3)}$ in 1989 first documented the utilization of the free fibula flap for mandibular reconstruction. This technique was quickly well-received due to its obvious advantages, as the flap provides a considerable length of bone (up to $25 \mathrm{~cm}$ ), adequately sized pedicle, low donor site morbidity, and capability of complex anterolateral defect reconstruction. Additionally, it included an unmatched ability to allow sufficient periosteal blood supply after osteotomy for the reconstruction of composite de- 
fects in multiple planes. ${ }^{4)}$ Thus, the free fibula flap has proven itself to be the "gold standard" for mandible reconstruction ${ }^{5)}$ and is currently the highest choice for maxillo-mandibular bony reconstruction in benign and malignant tumors. Previously, the technique was completely based on intraoperative subjective evaluation of the surgeon's skill for the post ablative outcome; resulting in numerous faulty and tedious manipulations to reform and reshape the bony discontinuity. Thus, the complex anatomy and mobility of the mandible, the threedimensional (3D) position of the free fibula flap, and microvascular anastomosing posed a challenge for surgeons to produce the perfect outcome. Moreover, longer operative duration prolongs the period of ischemia and the inability to restore the proper maxillomandibular and occlusal relationships, which finally results higher complication rates and poor cosmetic and functional outcomes. ${ }^{6}$ To overcome these drawbacks, there is a need for a more refined and improved technological development.

"Rapid prototyping" also known as "3D bio-printing" or "solid free-form fabrication" or "additive manufacturing" or 'layered manufacturing' is a new technology that introduces a technical and industrial revolution in the field of plastic and reconstructive surgery with benefits including enhanced accuracy, advanced operative efficiency, and desired outcomes in the surgical field. ${ }^{7.8)}$ This technology gradually places layers of materials to create 3D objects of material in a controlled manner rather than material reduction. The 3D printing concept started as "stereolithography (STL)" in the early 1980s by Charles, ${ }^{9)}$ where he introduced the novel 3D printer for business application in 1988. ${ }^{9}$ STL accelerates the fabrication of an object by curing a photo-reactive resin accompanied by an ultraviolet laser in a layer-by-layer design. A number of 3D printing processes have been used and implemented extensively; and since the early 2000s, the usage of such applications has been increasing. ${ }^{10)}$

\section{Surgical phase of virtual surgical planning (VSP) and 3D bio-printing technique}

The surgical phase consists of four phases ${ }^{11,12)}$

1. Surgical planning

2. Surgical modeling

3. Surgical technique

4. Surgical evaluation

The planning phase starts with strong-resolution computed tomographic (CT) scans of patient's craniofacial skeleton as well as CT angiography of lower extremities to study the do- nor site bone and vessels and then are sent to the required modeling company. An online teleconference is then held with the surgeons and a biomedical engineer finalizes the fundamental issues including cutting margins, osteotomies, position of the vascularized bone graft in oncologic reconstruction, perfect repositioning of the fractured bony segments (Figs. 1 and 2)

The modeling phase (Fig. 3) involves the construction of stereolithographic models in the area of the desired orofacial skeleton, specific cutting guides for both resection and vascularized bone graft, reconstruction plate or template for bending plate. These cutting guides and templates are made by clinician's preference. ${ }^{11)}$

Surgery phase incorporates the utilization of models, cutting guides, and plates. After securing the maxillo-mandibular fixation, osteotomies are made in the upper or lower jaw according to resection plan. Following the cutting guides, collected bony flap is cut and osteotomized in situ and before the whole composite unit is fixed into maxillary or mandibular gap, osseous flap is placed on the reconstruction plates. The refurbishment of bony architecture proceeds to restoration of soft tissue.

The evaluation phase is performed by the quantitative measurement of the post-surgical outcomes that proceeds the CT scan based on the similar pre-operative protocol; ${ }^{11)}$ and by the personalized appraisal regarding restoration of maxillofacial function by the patient and the clinician.

\section{Advantages and disadvantages of VSP and 3D bio-printing technique}

The advantages of classical pre-surgical planning for tumor resection include perfectly placed boundaries in safe tissue and cutting guide allowing duplication of planned osteotomies during surgery. It ensures precise photocopying of the mandibular contour with no bony deformities. The reconstructive plates can be designed by morphological mirroring of the sound cortical bone of the contralateral hemi-mandibular site for the tumor that alters unilateral outer mandibular cortical bone contour. Additionally, a library database can be used to adapt the proper dental occlusion.

In secondary reconstruction, a virtual environment allows the ideal preoperative planning of mandibular segment reposition; reproduce exact orientation/relation of the original (before initial surgery) mandibular segments. ${ }^{12,13)}$ The reconstructive bone plate can be designed using the original external cortical bone as a template by using CT data obtained before primary surgery. Finally, virtual orientation is more suitable 

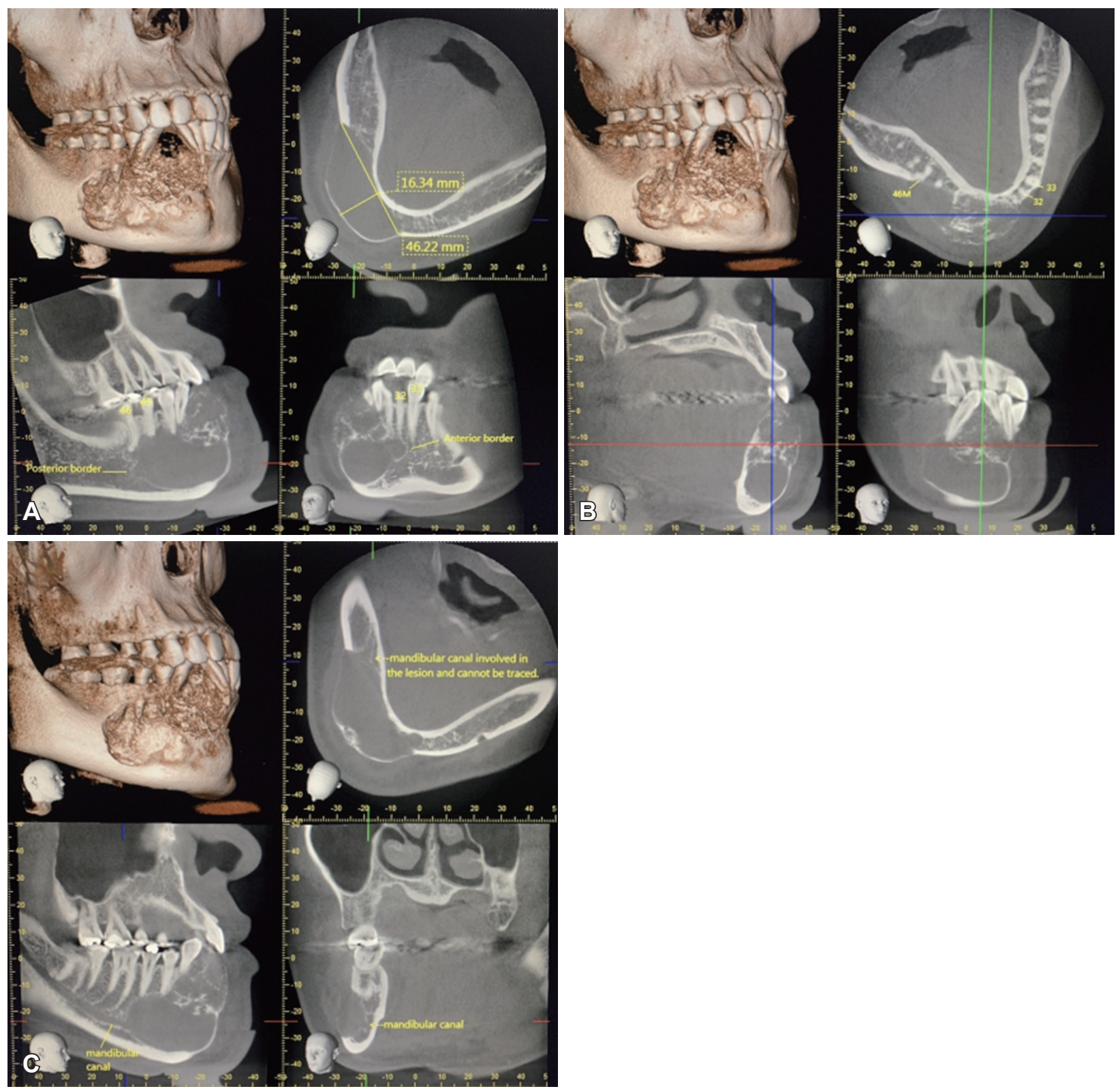

Fig. 1. Cone beam CT showing the desmoplastic lesion in different views. Anterior and posterior view of the lesion (A). Lingual cortex involvement (B). Involve inferior alveolar canal (C).

to select the fibular osseous fragment for future implant insertion. ${ }^{14)}$ Its sharp calculation is suitable to figure the bone length and free flap extension of the vascular pedicle.

Disadvantages primarily include the extra expenses for designing, extended time period required for virtual planning, prototyping malignant cases where the delay may increase the risk of malignant progression. Additionally, it is particularly difficult to adapt when intra-operative surgical plan of action differs (e.g., finding of positive margins on frozen section examination).

\section{Previous studies}

In this review, we sought to evaluate the benefits of $3 \mathrm{D}$ bioprinting and virtual surgical planning (VSP) technology by examining different literatures to find out its numerous implementations as shown in Table $1 .{ }^{15-26)} \mathrm{We}$ focused on investigating its increased bone contact, finer tooth alignment, improved facial esthetical outline, morphological consequences, functional outcome, duration of surgery, and reduced complication rates in comparison to the previously surgeon-reliant, intraoperative experimental 2D imaging techniques in this review. 


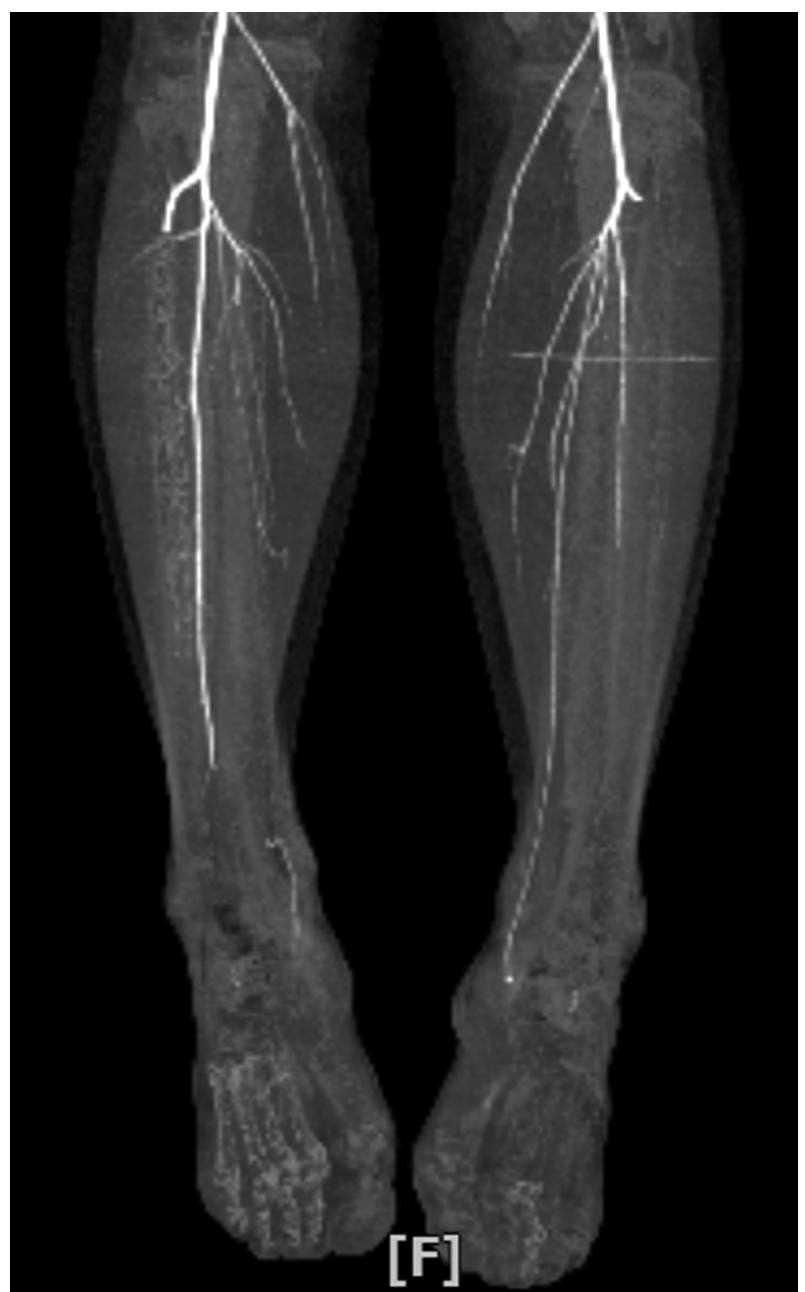

Fig. 2. Patient's CT angiography of lower extremities to assay the donor site bone and vessels.

\section{Discussion}

Table 2 provides the summary of previous articles concerning the use of VSP and 3D bio-printing in oncological resection of the mandible. While Table 3 illustrates the benefits of VSP reported from previous studies.

Reconstructed mandibular defects by free fibular flap described by Hidalgo ${ }^{3)}$ is dependent on surgeon's skill and decision which is usually experimental and lack communication between the surgical and reconstructive team, resulting in less precise reconstruction, longer procedural duration, longer ischemia period that frequently causes major complications with a rate ranging between $25 \%$ and $35 \%{ }^{6,27,28)}$ with the highest failure rate of $35 \%$ at the anterior region. ${ }^{29)}$ Advanced solutions like stereolithographic models with pre-bending plates and pre-plating technique described by Pellini, et al. ${ }^{30)}$ show that the further improvement of VSP on the accuracy of the pre-operative plan leads to greater precision of the surgical procedure and reduction of surgical time which has already been well documented. ${ }^{31-33)}$

The study by Succo, et al. ${ }^{15)}$ described the computer-assisted mandibular reconstruction technology in a step-by-step manner with the customized solution Synthes ProPlan CMF (Materialise, Leuven, Belgium) and demonstrates the virtual planning 3D bio-printing technology as an advanced approach for more accurate final reconstruction. They observed an excellent fit with pre-bent plates and bony contact on both mandible and fibula, reduced duration of ischemia times and operation, less complications and a shortened length of hospital stay. The authors mentioned that the stereolithic models facilitate pre-operative plate bending, prefabricated cutting guides ensure efficient osteotomies that minimized error and advanced safety of the whole procedure resulted more perfect reconstruction and reduction in surgical times, ensures remarkable reduction ischemia time by overcome any surgical manipulation that required for plate and bony contouring and fixation of the fibula even in an en-block resection with neck dissection. Laser surfaced plate presents sharp adaptation with the residual mandibular segment to a new mandibular contour and the plate does not weaken by manual bending, therefore results in a proper and new "mandible" position in the case of alter maxillomandibular relationship. Moreover, surgeons can pre-operatively plan the programmed positioning of fibular segments to provide places for future dental rehabilitation as well as placement of implant which is strongly effective especially for bone modification like onlay bone grafts and osteodistraction. This technology also preserves the cutaneous vessel and maintain proper direct blood flow to the skin island by pre-operative angiographic CT scan and eco-color Doppler which assists in deciding the correct position of the fibula cutting guide.

A similar type of study in 2016 by Wang, et al. ${ }^{18)}$ investigated the preciseness of the mandibular reconstruction and clinical outcomes in both virtual planning and conventional surgery group and the results found shorter ischemia time, shorter duration of operation with precise fit with the pre-bent plate, mandible, and fibula segments in the virtual planning group. The author mentioned that the experimental manipulation by the surgeon is the main drawback of conventional surgery which is successfully avoided by pre-operative VSP surgery and when clinicians become familiar with the same procedures by pre-operative planning, a more refined outcome of reconstructions can ensure. ${ }^{34)}$ Contrarily, a longer time during 

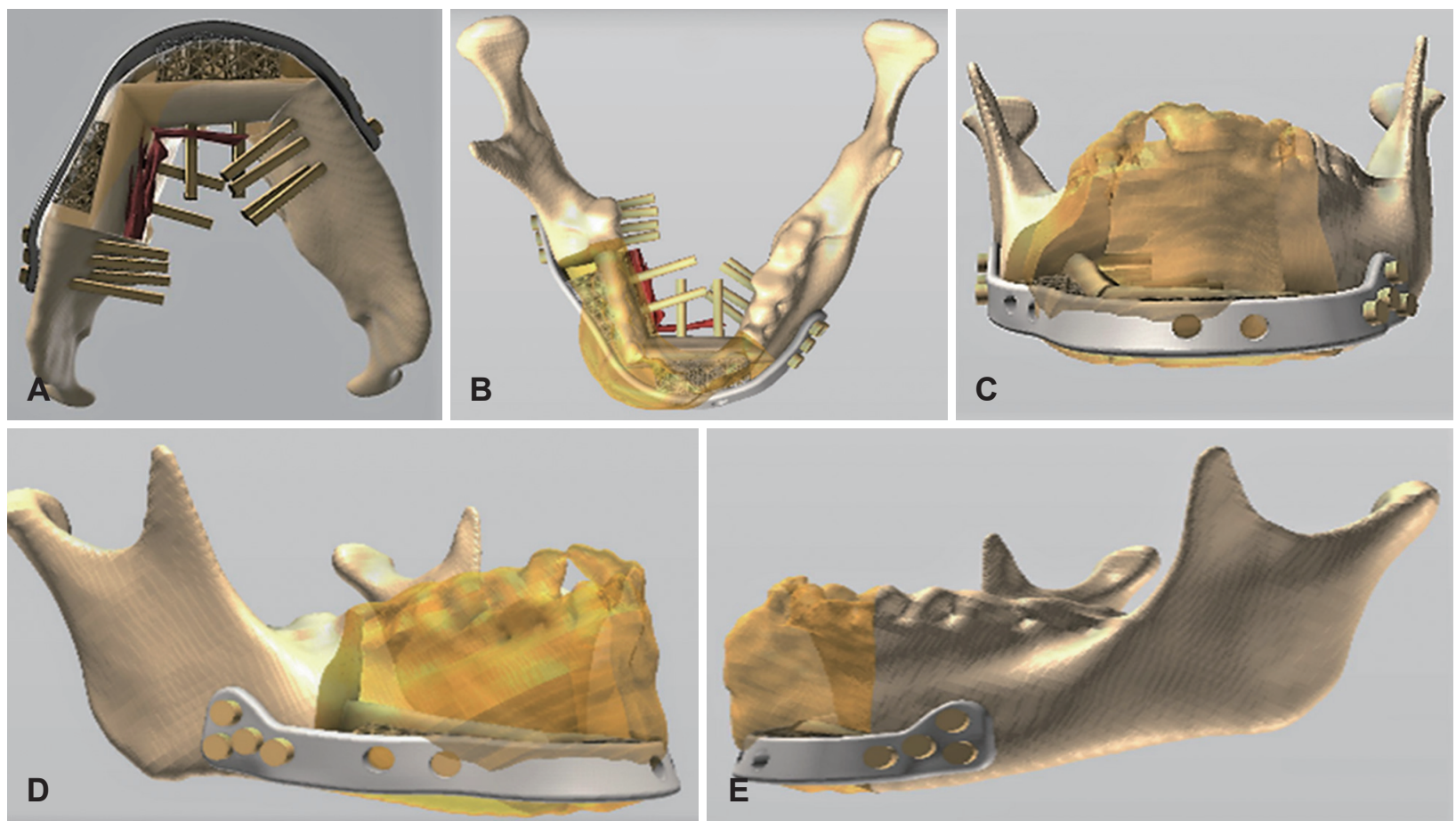

Fig. 3. Showed the step of 3D model printing of the mandible with the fixed prebent reconstruction titanium and screw. Virtual planning and prepared 3D model printing of the mandible with the fixed prebent reconstruction titanium and screw (A, B). Overlay of the virtually planned neomandible with pre-bent customized plate reconstruction with a pre-bent customized plate and screw evaluated by 3D CT (C-E). This is a sample case with diagnosis of benign lesion 'Desmoplastic Ameloblastoma' confirmed by the incisional biopsy at the Department of Oral and Maxillofacial Surgery, Mahidol University, Bangkok. 3D: three-dimensional.

pre-operative planning and model construction and the inability to confirm the surgical margins of soft tissues preoperatively until frozen section, are the limitations of VSP procedures.

The result was also found in the study by Ren, et al. ${ }^{23)}$ using the same protocol surgery containing pre-bent titanium plates and customized models with cutting guides for osteotomies compared to the conventional method. The author mentioned that the particular cases without oral squamous cell carcinoma (OSCC) and preoperative irradiation benefited more than OSCC having irradiation history cases.

Chang, et al. ${ }^{20)}$ also reported advanced precision of the actual osteotomies, low deviation rate from the preoperative plan, and significantly lower revising incidence of osteotomies with burring, cutting or using bone paste on the VSP group using stereolithic models, pre-bent plates, and osteotomy guides from CT-guided planning session compared to the control group that only used the stereolithic model as a template where reconstruction in the control group conducted by experienced surgeons and less experienced surgeons performed in the study group.

A systematic literature review with 33 papers of 220 patients of craniofacial oncological reconstruction along with virtual planning technology, reported both quantities and qual- itative benefits and enhanced accuracy of the reconstruction (93\%), shortened intraoperative duration $(80 \%)$, and overall success of all their variables. ${ }^{16)}$

The article of Toto, et al. ${ }^{17)}$ evaluated the scenario of CTguided preoperative planning using a pre-bent reconstruction plate that had been criticized for causing additional expense without any clear benefit. The authors used 3 groups in their study and the results showed that the group that used CT-guided preoperative planning and osteotomy guides with pre-bent reconstruction plates increased procedural efficiency and remarkably decreased costs and operative times. They evaluated that the extra expenditure compensated by the reduced duration in the operating room due to patient-specific guide which drastically improved procedural skill with less flap loss and complications.

Although computer-aided design and computer-aided modeling (CAD-CAM) method showed significant improvement in technical accuracy, long-term outcomes often showed aberrances of up to a few millimeters, and the causes remain unclear. Goormans, et al. ${ }^{26)}$ with his study tried to find-out repeating errors in the end-results and surgical outcome of virtually planned mandibular reconstructions. The comparison of the virtual plan and postoperative mandible model 


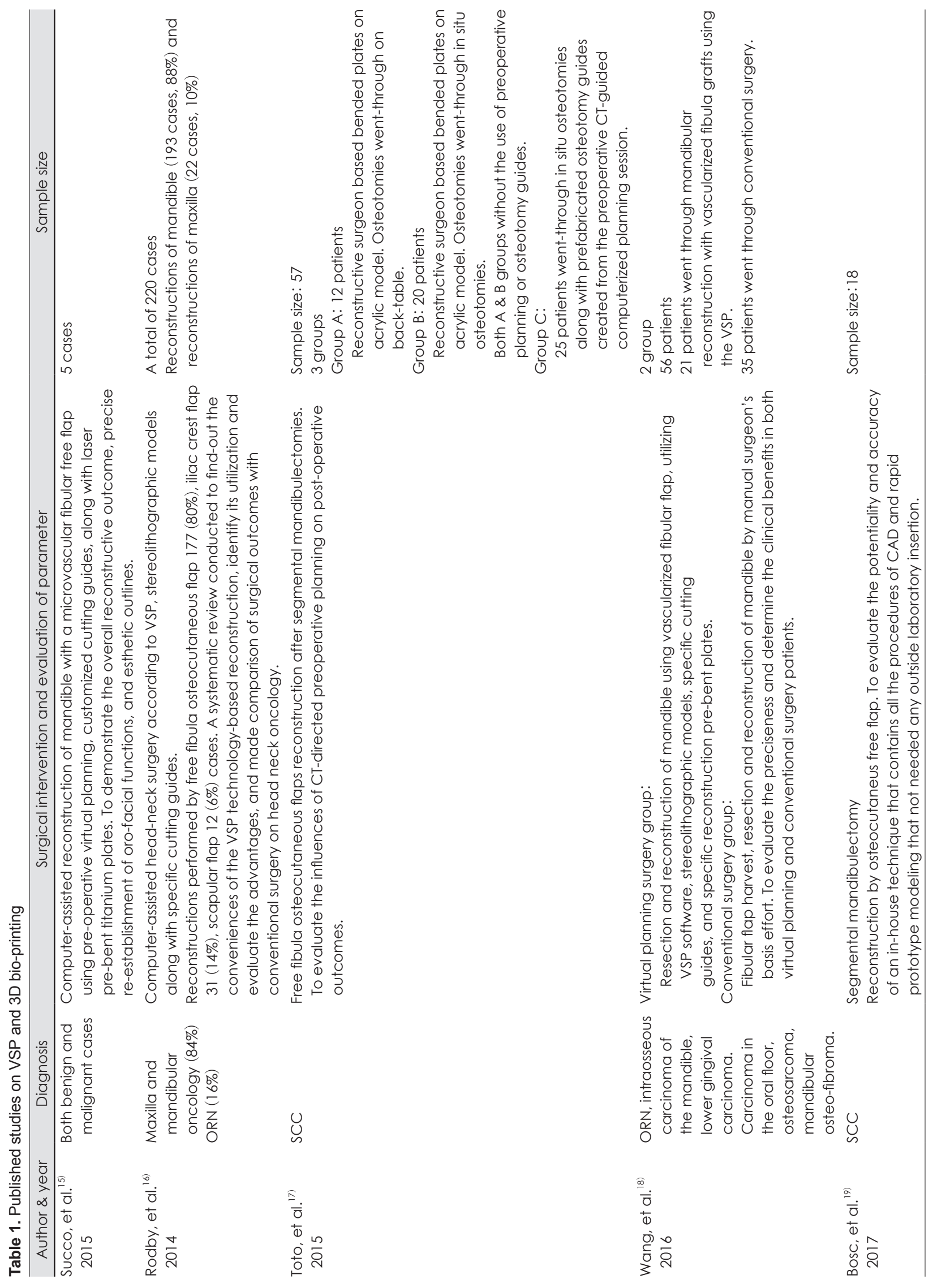




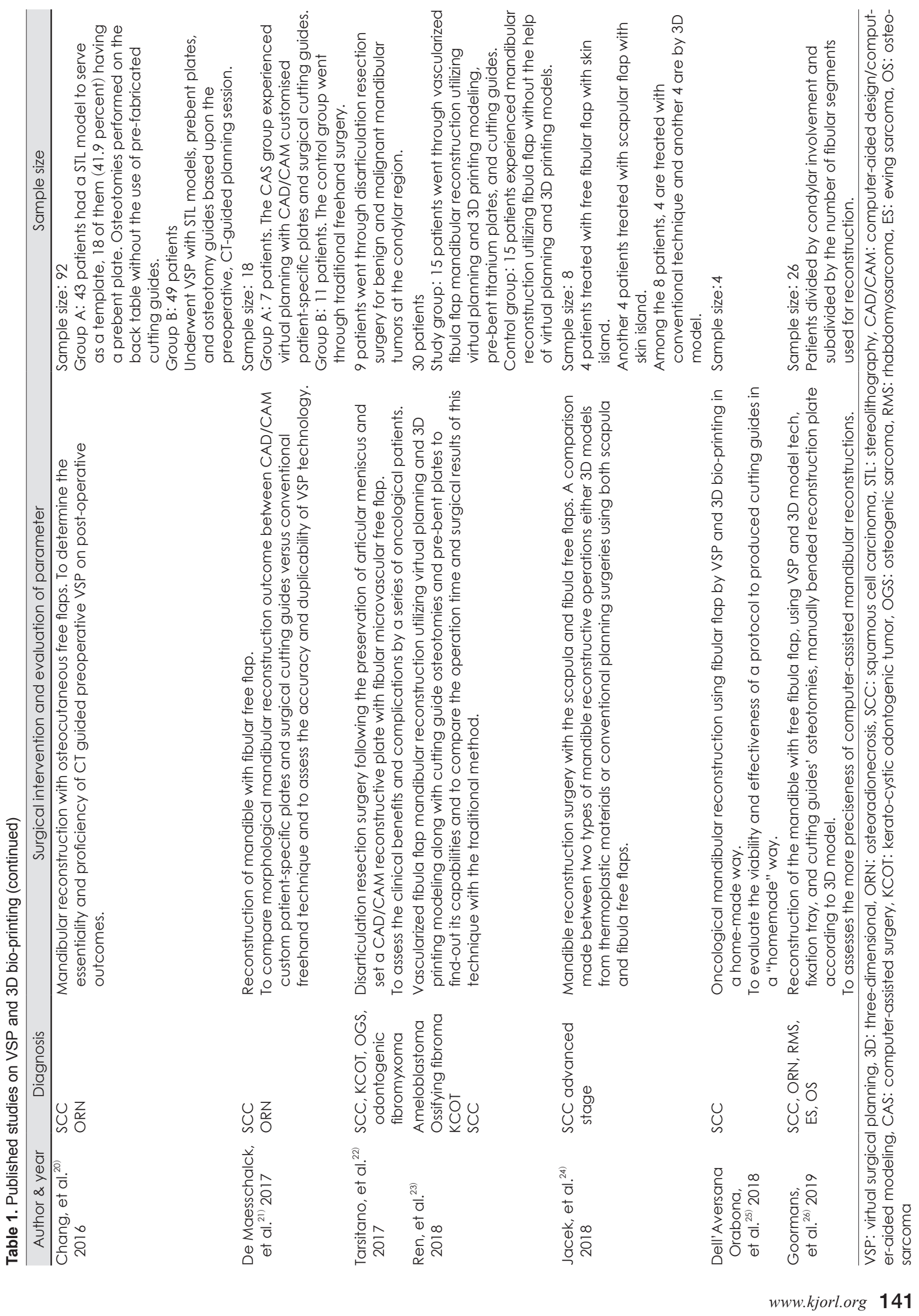


Table 2. Summary of previous articles concerning the use of VSP and 3D bio-printing in oncological resection of the mandible

\begin{tabular}{|c|c|c|}
\hline Author \& year & Follow-up & Result \\
\hline $\begin{array}{l}\text { Succo, et al. }{ }^{15)} \\
2015\end{array}$ & $8-12$ month & $\begin{array}{l}\text { Outstanding accuracy of cutting guides, perfectly fit pre-bent plates, precise bone contact, } \\
\text { and position found in mandible and fibula graft. } \\
\text { The average difference between the programed segment and CT control SL } 0.098 \pm 0.077 \mathrm{~cm} \text {. } \\
\text { Significantly shorter ischemia times an average of } 75 \pm 8 \mathrm{~min} \text {; Average post-operative hospital } \\
\text { stay } 18 \pm 3 \text { days. }\end{array}$ \\
\hline $\begin{array}{l}\text { Rodby, et al. }{ }^{16)} \\
2014\end{array}$ & $\begin{array}{l}\text { Mean } \\
\text { follow-up } \\
\text { month } \\
14 \text { months }\end{array}$ & $\begin{array}{l}\text { Total: } 33 \text { articles, } 220 \text { cases } \\
\text { Functional outcomes reported in } 99 \text { cases ( } 45 \%) \text {. } \\
2 \text { patients ( } 2 \% \text { ) categorized as 'ideal,' } 12 \text { patients ( } 12 \% \text { ) as 'outstanding,' } 23 \text { patients ( } 23 \% \text { ) as } \\
\text { good, } 34 \text { patients ( } 35 \% \text { ) as 'restored' and comments from patient and physician-expressed } \\
\text { satisfaction with function for } 7 \text { ( } 7 \% \text { ) and } 21 \text { ( } 21 \% \text { ) patients respectively. } \\
\text { Esthetical outcomes reported in } 84 \text { patients (38\%) and catagorized as 'outstanding' for } 34 \\
\text { patients ( } 41 \% \text { ) and 'good' in } 17 \text { patients ( } 20 \%) \text {; 'successful' for } 8 \text { patients ( } 10 \% \text { ); 'symmetry } \\
\text { achieved' for } 6 \text { patients ( } 7 \% \text { ); 'near normal' results in one patient; and patient and } \\
\text { physician- satisfaction revealed with the esthetic outcome for } 7 \text { ( } 8 \% \text { ) and } 11 \text { ( } 13 \% \text { ) of patients } \\
\text { respectively. } \\
\text { Precise accuracy of the reconstruction found on } 93 \% \text { of cases. } \\
\text { Shortened intraoperative time found in } 175 \text { cases ( } 80 \%) \text {. } \\
\text { Especially described reduced flap ischemic time for } 67 \text { cases ( } 30 \%) \text {. } \\
\text { User convenience especially reported for } 53 \text { cases ( } 24 \% \text { ). } \\
\text { Negative margin found as resection cutting guides in } 12 \text { cases ( } 5 \%) \text {. } \\
\text { Refined predictability of outcomes especially documented in } 16 \% \text { cases. } \\
22 \% \text { of the patients improved patient satisfaction. } \\
6 \% \text { of patients decreased complications. } \\
\text { Quantitative study data showed with an average score of } 88 \text { for patients from VSP and score } \\
68 \text { for traditionally reconstructed patients. } \\
\text { Quantitative results utilizing pre-operative and post-operative CT scan comparisons shown for } \\
30 \% \text { of cases. } \\
\text { Mean surface deviation in } 1 \text { case. } \\
\text { Repetition of segment placement found in } 7 \text { patients, and osteotomy site difference by plate } \\
\text { overlap found in } 11 \text { patients. The position, the difference from the actual postoperative and } \\
\text { projected CT images, all patients ( } 50 \text { cases total) were within } 2.5 \text { mm deviation/difference } \\
\text { and overlap in the actual vs. projected reconstructive plates was seen in } 11 \text { patients, } 58 \% \\
\text { ( } \pm 8.96 \% \text { ). }\end{array}$ \\
\hline $\begin{array}{l}\text { Toto, et al. }{ }^{17)} \\
2015\end{array}$ & $N / D$ & $\begin{array}{l}3 \text { groups, as mentioned in Table: } 1 \\
\text { Mean ischemia time } 177.8 \mathrm{~min}, 86.69 \mathrm{~min} \text {, and } 76.92 \mathrm{~min} \text { for group A, B, and C respectively. } \\
\text { Mean OR time } 706.9 \mathrm{~min}, 659.8 \mathrm{~min}, 534.2 \mathrm{~min} \text { for group A, B and C respectively. Mean } \\
\text { operating room values } \$ 20332.50, \$ 19002.60, \$ 15450.48 \text { for group A, B, C respectively. } \\
\text { Cost of plate } \$ 4200.00, \$ 4200.00, \$ 5500.00 \text { for group A, B and C groups respectively. } \\
\text { Total costs } \$ 24532.50, \$ 23202.60, \$ 20950.48 \text { for group A, B and C respectively. }\end{array}$ \\
\hline $\begin{array}{l}\text { Wang, et al. }{ }^{18)} \\
2016\end{array}$ & 6 months & $\begin{array}{l}\text { Ischemia period (mean } \pm \text { SD) found } 45 \pm 13 \text { min in VSP group where } 63 \pm 15 \text { min in CS group, } \\
\text { Total operation duration (mean } \pm \text { SD) } 4.5 \pm 0.9 \mathrm{hr} \text {. in VSP group and } 5.8 \pm 1.3 \mathrm{hr} \text { in CS group. } \\
\text { Normal condyle position achieved } 100 \% \text { in the VSP group and } 54.3 \% \text { in the CS group. Sharp } \\
\text { bone to bone contact found } 95.2 \% \text { in the VSP group and } 71.4 \% \text { in the CS group. Accurate } \\
\text { position among plate in mandible and fibula segment achieved } 95.2 \% \text { in the VSP group and } \\
62.9 \% \text { in the CS group. Good facial appearance achieved } 95.2 \% \text { in the VSP group and } 77.1 \% \\
\text { in the CS group. } 100 \% \text { of patients have their regular diet in the VSP group where CS group } \\
85.7 \% .100 \% \text { of patients have their intelligible speech in the VSP group and } 97.1 \% \text { in the CS } \\
\text { group. }\end{array}$ \\
\hline $\begin{array}{l}\text { Bosc, et al. }{ }^{19)} \\
2017\end{array}$ & 19 months & $\begin{array}{l}\text { All reconstruction outcomes successfully matched between the pre-operative model and final } \\
\text { surgery outcome both the fibula bone segments and angle measurements. } \\
\text { No major modification needed for any patient. The mean variation in angle value between } \\
\text { the preoperative models to postoperative outcomes } 4^{\circ} \text {. }\end{array}$ \\
\hline
\end{tabular}


Virtual Planning and 3D Bio-Printing for Mandibular Reconstruction I Shuborna NS, et al.

Table 2. Summary of previous articles concerning the use of VSP and 3D bio-printing in oncological resection of the mandible (continued)

\begin{tabular}{|c|c|c|}
\hline Author \& year & Follow-up & Result \\
\hline $\begin{array}{l}\text { Chang, et al. }{ }^{20)} \\
2016\end{array}$ & 12 months & $\begin{array}{l}\text { Preoperative CT-guided surgery resulted less burring, lesser osteotomy revisions, and little bone } \\
\text { grafting, decreased operative time ( } 666 \text { minutes for VSP group } 545 \text { minutes for conventional } \\
\text { surgery group; } \mathrm{p}<0.005 \text { ), decreased bony nonunion. }\end{array}$ \\
\hline $\begin{array}{l}\text { De Maesschalck, } \\
\text { et al. }^{21)} 2017\end{array}$ & & $\begin{array}{l}\text { Morphometric accuracy, from pre- and postoperative linear and angular measurements } \\
\text { found no statistically significant variences in both groups but only for the axial angle on the } \\
\text { non-affected side ( } 1.0 \text { in the CAS group versus } 2.9 \text { in the control group; } p=0.03 \text { ). }\end{array}$ \\
\hline & & $\begin{array}{l}\text { In the CAS group, a mean distance deviation of } 2.3 \pm 1.0 \mathrm{~mm} \text { for mandibular osteotomies and } \\
1.9 \pm 1.1 \mathrm{~mm} \text { for fibular osteotomies. }\end{array}$ \\
\hline
\end{tabular}

Tarsitano, et al. ${ }^{22)} \quad 2-72$ months, Only 1 patient had condylar displacement anterior to the glenoid tubercle, other patients had 2017 mean usual mouth opening.

24.8 month All patients developed low-grade mandibular deviation during maximum mouth opening. Chewing ability, speech style, and esthetical facial contour equivalent to or better than baseline for all patients.

The average postoperative condylar deviation from the preoperative location about $3.8 \mathrm{~mm}$ (range: 1.3 to $6.7 \mathrm{~mm}$ ).

Ren, et al. ${ }^{23)} 2018$

Reconstructive time hours and operative time hours on CAS group about $1.60 \pm 0.38$ hrs and $5.54 \pm 0.50$ hrs respectively where control group reconstructive times hours and operative times hours about $2.58 \pm 0.45$ and $6.54 \pm 0.70$ respectively and the $p$-value is $<0.001$. CAS group showed Intercondylar distance, intergonial angle distance, anteroposterior distance, gonial angles $2.92 \pm 1.15,2.93 \pm 1.19,4.31 \pm 1.24,3.85 \pm 1.68$ respectively and in control group $4.48 \pm 1.41,4.79 \pm 1.48,5.61 \pm 1.41,5.88 \pm 2.12$ respectively.

Jacek, et al. ${ }^{24)}$ 2018 Stability reported at conventional technology $84 \%$ and model 3D printing group $100 \%$, mouth opening $2.5 \mathrm{~cm}$ for conventional technology group $3 \mathrm{~cm}$ for model 3D printing group. Chewing function restored results $72 \%$ on the conventional group and $90 \%$ on model $3 \mathrm{D}$ printing group. Cosmetically acceptable and operation time $60 \%$ and $8.5 \mathrm{hr}$ respectively for the conventional group and $100 \%$ and 6.5 hrs respectively for Model 3D printing group. Mandibular counter symmetrical angle different $10.0 \pm 12.5 \mathrm{~mm}$ for the conventional group and 7.3 $\pm 9.1 \mathrm{~mm}$ for Model 3D printing group.

Dell'Aversana Orabona, et al. ${ }^{25)} 2018$

All mandibular reconstructions were fruitful with a perfect match from the digitally planned $3 D$ models to the final outcomes. No big adjustment of the mandibular bone resection needed in intra-operatively as suggested to the planned 3D simulation. The total period taken for the virtual planning design was about $3 \mathrm{~h} .6 \mathrm{~h}$ were required for the printing process and sterilization. An average distance of $1.631 \mathrm{~mm}$ (range 0.594 to 4.067 ) and a SD of $5.496 \mathrm{~mm}$ (range 1.966 to 8.024 ).

Goormans, et al. ${ }^{26)} 2019$ 50 fibular segments evaluation

The mean deviation in fibular SL is $1.74 \mathrm{~mm}$ (range, $0.02-6.10 \mathrm{~mm}$ ), the angular deviation of the osteotomy planes is $1.98^{\circ}$ (range, $0.04-5.86^{\circ}$ ).

Mean values for each measure were intercoronoid distance deviation, $3.86 \mathrm{~mm}$ (range, 0.20-11.21 mm); interregional distance deviation, $3.14 \mathrm{~mm}$ (range, 0.05-8.28 mm); anteroposterior distance deviation, $2.92 \mathrm{~mm}$ (range, 0.03-8.49 mm); and intersegmental plane shift, $11.00^{\circ}$ (range, $2.76-24.15^{\circ}$ ). These results illustrated dissimilarities in a large scale in final postoperative accuracy.

In the group with preserved condyles, mean intercoronoid and interregional deviations differed significantly $(5.02 \mathrm{~mm}$ and $4.88 \mathrm{~mm}$, respectively; both $\mathrm{p}<0.05)$ for one-segmented and three-segmented fibular reconstructions, respectively. Final postoperative accuracy lessens when more fibular segments are utilized for reconstruction. For intersegmental plane shift, the preserved and non-preserved condyle groups vary significantly $\left(7.18^{\circ} ; \mathrm{p}<0.05\right)$.

General ischemia period found $<4.00 \mathrm{~h}$ where most ischemia times found $<2.00 \mathrm{~h}$.

The all-inclusive survival rate of fibular flaps $96.15 \%$.

VSP: virtual surgical planning, 3D: three-dimensional, SL: segment lengths, N/D: no difference, OR: odds ratio, SD: standard deviation, CS: conventional surgery, CAS: computer-assisted surgery 


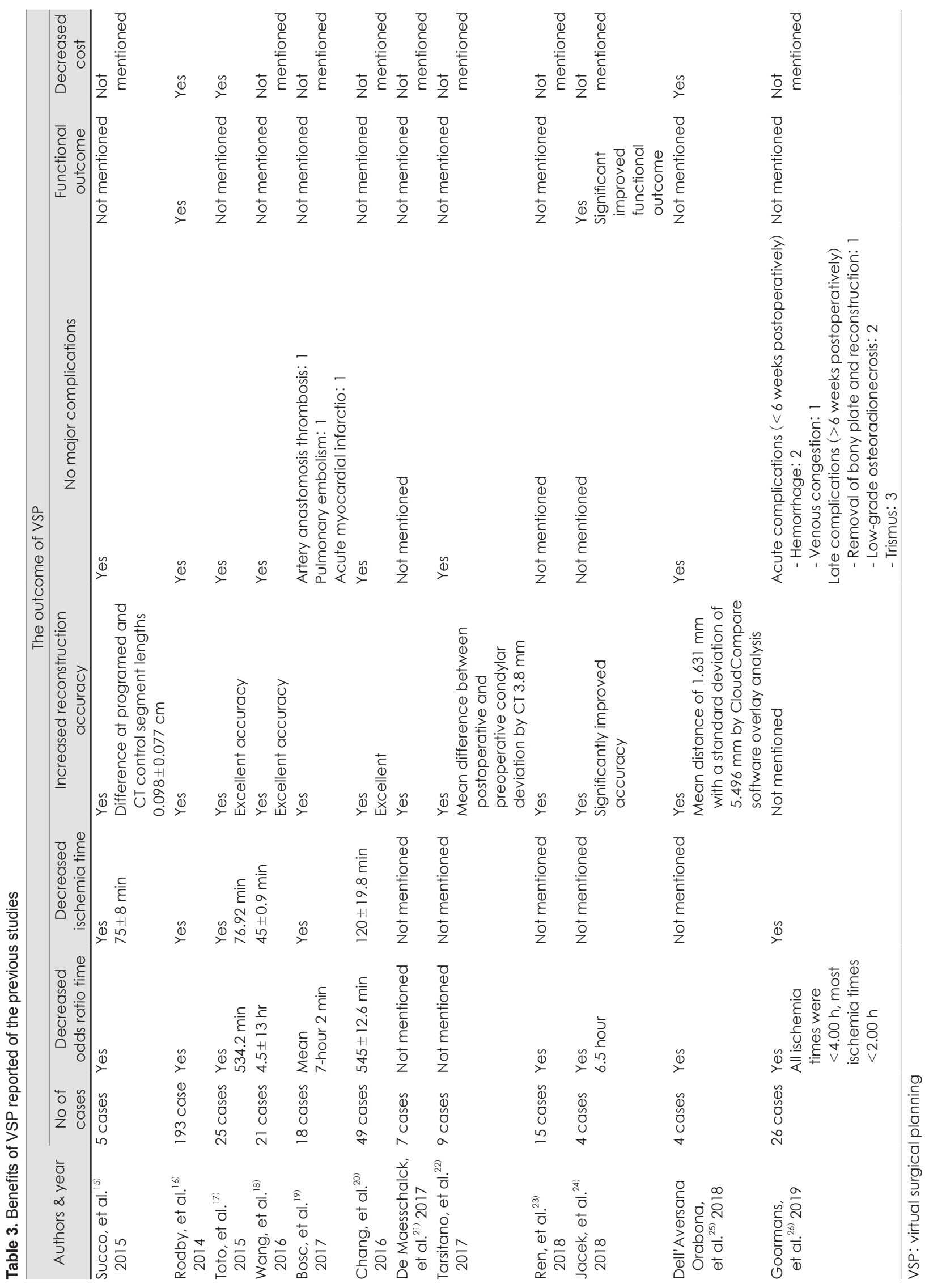


showed a mean segment length deviation of $1.74 \mathrm{~mm}$, which is similar to previous studies. The mean angular deviation of osteotomy planes was $1.98^{\circ}$ and demonstrated a minor difference between the pre and post fibular osteotomy angles. The author focused the significance of using fixation method that can guarantee the accuracy of the preoperative plan.

Currently, the progression of virtual reconstruction technology to 3D reconstruction from CT-scan, Digital Imaging and Communications in Medicine images, virtualization of the reconstruction project, and customized cutting guides are mostly outsourced and are often expensive, which present financial constraints to the health care system. The time for manufacturing is often longer than 3 weeks, which inevitably can increase the risk of cancer progression. Therefore, open-source freeware and material proposed to minimize those obstacles, which has been described by many surgeons all over the world. ${ }^{35)}$ The study of Bosc, et al. ${ }^{19)}$ mentioned that the total usage for CAD-CAM system expenditure range from 3000 to 5000 Euros per patient and the delivery period is longer than three weeks which may increase the risk of cancer progression and spread. They evaluated the potentiality and accuracy of an in-house technique that combines all the actions of CAD and rapid prototype modeling technologies and is easier and more affordable with maximum print volume and a printing resolution using layer plastic deposition and does not require any insertion of external laboratory. Their results showed that all reconstruction processes successfully matched between the pre-operative model and final surgical outcome of both fibula bone segments and angle measurement without any major modifications. The buying price of the 3D printer will drastically be shortened by the duration and procedure cost as the time reduced about $24 \mathrm{~h}$ to manufacture the customized cutting guides in compared to commercial systems. Dell'Aversana Orabona, et al. ${ }^{25)}$ also investigated the reliability and efficiency of the proposed algorithm of CAD-CAM system using free open source software for digital planning with 3D layer plastic deposition printer and cutting guides produced in a "homemade" way. The results stated in the article discovered excellent accuracy of bony fit.

The aim of reconstructive surgery is to return-back the outline of the lower one-third of the face, conserve chewing function, keep normal occlusion, and furnish a higher chance for future dental implant placement and sound movement of the temporomandibular joint (TMJ). The study by Jacek, et al. ${ }^{24)}$ assessed the comparative functionality (stability of junction, mobility, mastication ability) and cosmetics in advanced squa- mous cell carcinoma cases and found significantly better outcome, decreased operation time and re-contour preferable outline and esthetic outcome within the $1 / 3$ of the lower face in VSP group compared to traditional surgery group. The author mentioned this technology can reconstruct large segmental defects, reduce the period of osseointegration of the donor graft site, and minimize the danger of bone resorption as well as pathological fractures.

Study of De Maesschalck, et al. ${ }^{21)}$ found fine accuracy and reproducibility by fibular free flap with 3D VSP compared with conventional surgery group to evaluate the morphology of mandibular reconstruction. Hanasono and Skoracki ${ }^{36)}$ first assessed the morphological differences by analyzing the pre- and postoperative position of bony landmarks like gonion, gnathion, and condyle in patients undergoing mandibular reconstruction and found a statistically remarkable improvement of position deviations, accuracy in linear fibular length and angular measurements of osteotomy lines from planned to actual reconstruction. Zhang, et al. ${ }^{37)}$ also found significantly less intercondylar distance, anteroposterior distance, intergonial angle distance gonial angle in the computer-assisted surgery group versus conventional surgery group.

Reconstruction of condyle with alloplastic materials still possess a significant challenge to functional reconstruction in the anatomical region. Study by Tarsitano, et al. ${ }^{22)}$ researched cancer resection and preservation of articular meniscus through CAD/CAM reconstructive plate with microvascular fibular free flap where head of the prosthetic condyle recreate the anatomy. Their result found no plate exposure on clinical examination; no joint pain and no plate loosening, no resorption of the glenoid fossa found compared to pre- and postoperative CT. Many studies regarding TMJ prostheses and the long-term results stand mixed and controversial on the reconstructive perspectives. Patel and Maisel $^{38)}$ described significant complications like malocclusion, infection, plate exposures in irradiated patients, neurosensory hearing loss after malignant tumor removal. On the other hand, Daniel and Browne, ${ }^{39)}$ Carlson $^{40)}$ reported positive results like no exposure of plate, dislocation, malocclusion even in patients undergoing radiation therapy. As the CAD/CAM technology permits prototyping of the complete metal photocopy of pre-operative native condyle, articulatory surface accurately can be smooth; preserve disc and upper TMJ chamber and the lack of anatomical changes block biodynamic modifications in tissues of articulation chamber. Thus, results no disadvantageous reaction to the condylar prosthesis. 


\section{Conclusion}

VSP presents a revolutionary technology that brings oncological head-neck reconstruction into the latest era which can ensure highly expected advanced reconstructive outcomes in both facial impression as well as functional purposes. Application of VSP-3D bio-printing technology into each stage of the reconstruction process provides the chance to reduce man-made translational mistakes with each stage of the surgical process. However, it still possesses some limitations due to the variables inherent in complex reconstruction that still need to be programmed into the computer algorithm. For more advanced programs, soft-tissue reconstruction and coverage, osteo-septo-cutaneous fibula flap components, including the septo-cutaneous vessels and the inter-component relationship, bone cross-section and nutrition, pedicle reach, and surgical plan flexibility are important points to be considered. Young surgeons are encouraged to learn the classic method first. Adopting the currently available technology can help young reconstructive surgeons increase their efficiency and surgical outcomes.

\section{Acknowledgments}

The authors would like to thank Christian Estacio for editing and revising the language of this manuscript.

\section{Author Contribution}

Conceptualization: Teeranut Chaiyasamut, Nadia Sultana Shuborna. Data curation: Nadia Sultana Shuborna, Natthamet Wongsirichat. Formal analysis: Natthamet Wongsirichat. Investigation: Nadia Sultana Shuborna. Methodology: Nadia Sultana Shuborna, Bishwa Prakash Bhattarai, Natthamet Wongsirichat. Project administration: Nadia Sultana Shuborna, Sirichai Kiattavornchareon, Natthamet Wongsirichat. Resources: Natthamet Wongsirichat. Supervision: Teeranut Chaiyasamut. Validation: Teeranut Chaiyasamut. Visualization: Bishwa Prakash Bhattarai, Sirichai Kiattavornchareon. Writing-original draft: Nadia Sultana, Shuborna Natthamet Wongsirichat. Writing - review and editing: Bishwa Prakash Bhattarai, Teeranut Chaiyasamut.

\section{ORCIDs}

Natthamet Wongsirichat

Nadia Sultana Shuborna

Bishwa Prakash Bhattara

Teeranut Chaiyasamut

Sirichai Kiattavorncharoen https://orcid.org/0000-0001-6766-9188

\section{REFERENCES}

1) Rogers SN, Devine J, Lowe D, Shokar P, Brown JS, Vaugman ED. Longitudinal health-related quality of life after mandibular resection for oral cancer: A comparison between rim and segment. Head Neck 2004;26(1):54-62.

2) Tarsitano A, Pizzigallo A, Ballone E, Marchetti C. Health-related quality of life as a survival predictor for patients with oral cancer: Is quality of life associated with long-term overall survival? Oral Surg Oral Med Oral Pathol Oral Radiol 2012;114(6):756-63.

3) Hidalgo DA. Fibula free flap: A new method of mandible reconstruction. Plast Reconstr Surg 1989;84(1):71-9.

4) Wallace CG, Chang YM, Tsai CY, Wei FC. Harnessing the potential of the free fibula osteoseptocutaneous flap in mandible reconstruction. Plast Reconstr Surg 2010;125(1):305-14.

5) Hidalgo DA, Rekow A. A review of 60 consecutive fibula free flap mandible reconstructions. Plast Reconstr Surg 1995;96(3):585-96; discussion 597-602.

6) van Gemert JTM, van Es RJJ, Rosenberg AJWP, van der Bilt A, Koole R, Van Cann EM. Free vascularized flaps for reconstruction of the mandible: Complications, success, and dental rehabilitation. J Oral Maxillofac Surg 2012;70(7):1692-8.

7) Antony AK, Chen WF, Kolokythas A, Weimer KA, Cohen MN. Use of virtual surgery and stereolithography-guided osteotomy for mandibular reconstruction with the free fibula. Plast Reconstr Surg 2011;128(5):1080-4

8) Bell RB, Weimer KA, Dierks EJ, Buehler M, Lubek JE. Computer planning and intraoperative navigation for palatomaxillary and mandibular reconstruction with fibular free flaps. J Oral Maxillofac Surg 2011;69(3):724-32.

9) Gross BC, Erkal JL, Lockwood SY, Chen C, Spence DM. Evaluation of 3D printing and its potential impact on biotechnology and the chemical sciences. Anal Chem 2014;86(7):3240-53.

10) Ventola CL. Medical applications for $3 D$ printing: Current and projected uses. P T 2014;39(10):704-11.

11) Lethaus B, Poort L, Böckmann R, Smeets R, Tolba R, Kessler P. Additive manufacturing for microvascular reconstruction of the mandible in 20 patients. J Craniomaxillofac Surg 2012;40(1):43-6.

12) Ciocca L, De Crescenzio F, Fantini M, Scotti R. CAD/CAM and rapid prototyped scaffold construction for bone regenerative medicine and surgical transfer of virtual planning: A pilot study. Comput Med Imaging Graph 2009;33(1):58-62.

13) Ciocca L, Mazzoni S, Fantini M, Persiani F, Baldissara P, Marchetti $\mathrm{C}$, et al. A CAD/CAM-prototyped anatomical condylar prosthesis connected to a custom-made bone plate to support a fibula free flap. Med Biol Eng Comput 2012;50(7):743-9.

14) Mazzoni S, Marchetti C, Sgarzani R, Cipriani R, Scotti R, Ciocca L. Prosthetically guided maxillofacial surgery: Evaluation of the accuracy of a surgical guide and custom-made bone plate in oncology patients after mandibular reconstruction. Plast Reconstr Surg 2013; 131(6):1376-85.

15) Succo G, Berrone M, Battiston B, Tos P, Goia F, Appendino P, et al. Step-by-step surgical technique for mandibular reconstruction with fibular free flap: Application of digital technology in virtual surgical planning. Eur Arch Otorhinolaryngol 2015;272(6):1491-501.

16) Rodby KA, Turin S, Jacobs RJ, Cruz JF, Hassid VJ, Kolokythas A, et al. Advances in oncologic head and neck reconstruction: Systematic review and future considerations of virtual surgical planning and computer aided design/computer aided modeling. J Plast Reconstr Aesthet Surg 2014;67(9):1171-85.

17) Toto JM, Chang EI, Agag R, Devarajan K, Patel SA, Topham NS. Improved operative efficiency of free fibula flap mandible reconstruction with patient-specific, computer-guided preoperative planning. Head Neck 2015;37(11):1660-4

18) Wang YY, Zhang HQ, Fan S, Zhang DM, Huang ZQ, Chen WL, et al. Mandibular reconstruction with the vascularized fibula flap: Comparison of virtual planning surgery and conventional surgery. Int J Oral Maxillofac Surg 2016;45(11):1400-5.

19) Bosc R, Hersant B, Carloni R, Niddam J, Bouhassira J, De Kermadec $\mathrm{H}$, et al. Mandibular reconstruction after cancer: An in-house approach to manufacturing cutting guides. Int J Oral Maxillofac 
Surg 2017;46(1):24-31.

20) Chang EI, Jenkins MP, Patel SA, Topham NS. Long-term operative outcomes of preoperative computed tomography-guided virtual surgical planning for osteocutaneous free flap mandible reconstruction. Plast Reconstr Surg 2016;137(2):619-23.

21) De Maesschalck T, Courvoisier DS, Scolozzi P. Computer-assisted versus traditional freehand technique in fibular free flap mandibular reconstruction: A morphological comparative study. Eur Arch Otorhinolaryngol 2017;274(1):517-26.

22) Tarsitano A, Battaglia S, Ramieri V, Cascone P, Ciocca L, Scotti R, et al. Short-term outcomes of mandibular reconstruction in oncological patients using a $\mathrm{CAD} / \mathrm{CAM}$ prosthesis including a condyle supporting a fibular free flap. J Craniomaxillofac Surg 2017;45(2):330-7.

23) Ren W, Gao L, Li S, Chen C, Li F, Wang Q, et al. Virtual planning and $3 \mathrm{D}$ printing modeling for mandibular reconstruction with fibula free flap. Med Oral Patol Oral Cir Bucal 2018;23(3):e359-66.

24) Jacek B, Maciej P, Tomasz P, Agata B, Wiesław K, Radosław W, et al. $3 \mathrm{D}$ printed models in mandibular reconstruction with bony free flaps. J Mater Sci Mater Med 2018;29(3):23.

25) Dell'Aversana Orabona G, Abbate V, Maglitto F, Bonavolontà $P$, Salzano G, Romano A, et al. Low-cost, self-made CAD/CAMguiding system for mandibular reconstruction. Surg Oncol 2018; 27(2):200-7.

26) Goormans F, Sun Y, Bila M, Schoenaers J, Geusens J, Lübbers HT, et al. Accuracy of computer-assisted mandibular reconstructions with free fibula flap: Results of a single-center series. Oral Oncol 2019;97:69-75.

27) Rana M, Warraich R, Kokemüller H, Lemound J, Essig H, Tavassol $\mathrm{F}$, et al. Reconstruction of mandibular defects - clinical retrospective research over a 10-year period -. Head Neck Oncol 2011;3:23.

28) Urken ML, Buchbinder D, Costantino PD, Sinha U, Okay D, Lawson W, et al. Oromandibular reconstruction using microvascular composite flaps: Report of 210 cases. Arch Otolaryngol Head Neck Surg 1998;124(1):46-55.

29) Boyd JB, Mulholland RS, Davidson J, Gullane PJ, Rotstein LE, Brown DH, et al. The free flap and plate in oromandibular reconstruction: Long-term review and indications. Plast Reconstr
Surg 1995;95(6):1018-28.

30) Pellini R, Mercante G, Spriano G. Step-by-step mandibular reconstruction with free fibula flap modelling. Acta Otorhinolaryngol Ital 2012;32(6):405-9.

31) Patel A, Levine J, Brecht L, Saadeh P, Hirsch DL. Digital technologies in mandibular pathology and reconstruction. Atlas Oral Maxillofac Surg Clin North Am 2012;20(1):95-106.

32) Foley BD, Thayer WP, Honeybrook A, McKenna S, Press S. Mandibular reconstruction using computer-aided design and computer-aided manufacturing: An analysis of surgical results. J Oral Maxillofac Surg 2013;71(2):e111-9.

33) Levine JP, Patel A, Saadeh PB, Hirsch DL. Computer-aided design and manufacturing in craniomaxillofacial surgery: The new state of the art. J Craniofac Surg 2012;23(1):288-93.

34) Saad A, Winters R, Wise MW, Dupin CL, St Hilaire H. Virtual surgical planning in complex composite maxillofacial reconstruction. Plast Reconstr Surg 2013;132(3):626-33.

35) Jalbert F, Boetto S, Nadon F, Lauwers F, Schmidt E, Lopez R. Onestep primary reconstruction for complex craniofacial resection with PEEK custom-made implants. J Craniomaxillofac Surg 2014; 42(2):141-8.

36) Hanasono MM, Skoracki RJ. Computer-assisted design and rapid prototype modeling in microvascular mandible reconstruction. Laryngoscope 2013;123(3):597-604.

37) Zhang L, Liu Z, Li B, Yu H, Shen SG, Wang X. Evaluation of computer-assisted mandibular reconstruction with vascularized fibular flap compared to conventional surgery. Oral Surg Oral Med Oral Pathol Oral Radiol 2016;121(2):139-48.

38) Patel A, Maisel R. Condylar prostheses in head and neck cancer reconstruction. Arch Otolaryngol Head Neck Surg 2001;127(7): 842-6.

39) Daniel E, Browne JD. Minimizing complications in the use of titanium condylar head reconstruction prostheses. Otolaryngol Head Neck Surg 2004;130(3):344-50.

40) Carlson ER. Disarticulation resections of the mandible: A prospective review of 16 cases. J Oral Maxillofac Surg 2002;60(2):176-81.

\section{정답 및 해설}

답 (5)

해 설 측인두절개술(lateral pharyngotomy)로 구인두에 접근하는 장면. 사진에서 보이는 구조는 설하신경과 설동맥이다. 추가로 상후두신경은 갑상연골막을 통과하여 진행하므로 측인두절개술 시 손상될 수 있어 주의해야 한다. 